\title{
Application of ultrasound contra infection with secondary hydatidosis in mice
}

\author{
B.B. Ramdan and A.A. Ali \\ Department of Biology, College of Education for Pure Sciences; University of Mosul, Mosul, Iraq

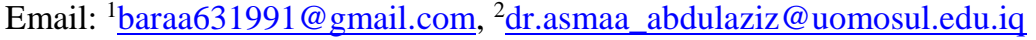

(Received September 23, 2019; Accepted October 21, 2019; Available online July 23, 2020)

\begin{abstract}
The present research explained the impact of ultrasound on the viability of Echinococcus granulosus protoscolices in vitro application of fixed frequency waves at 20000 pulse/sec and $1.8 \mathrm{w} / \mathrm{cm}^{2}$, with different exposing periods, thirty, twenty, fifteen, twelve, ten and five seconds respectively, subsequently prevention of mice against interjected with minor hydatid cysts, in comparison with the control animals infected with protoscolices without exposure to ultrasound waves, depending on many criteria including the numbers, weights and diameters of developed hydatid cysts. The results displayed an obvious impact of ultrasound waves on Echinococcus granulosus protoscolices viability number by increase of exposure period in vitro, in addition to a decrease of $100 \%$ of hydatid cysts numbers in the dealt ones with $17 \%$ fertility exposed for 20 seconds, the reduction rate was $99.23 \%$ in the group of fertility $35 \%$ which exposed for 15 seconds, after four and five months of infection.
\end{abstract}

Keywords: Echinococcus granulosus, Ultra Sonication, Hydatidosis, Mice

DOI: 10.33899/ijvs.2019.126132.1240, (O2020, College of Veterinary Medicine, University of Mosul.

This is an open access article under the CC BY 4.0 license (http://creativecommons.org/licenses/by/4.0/).

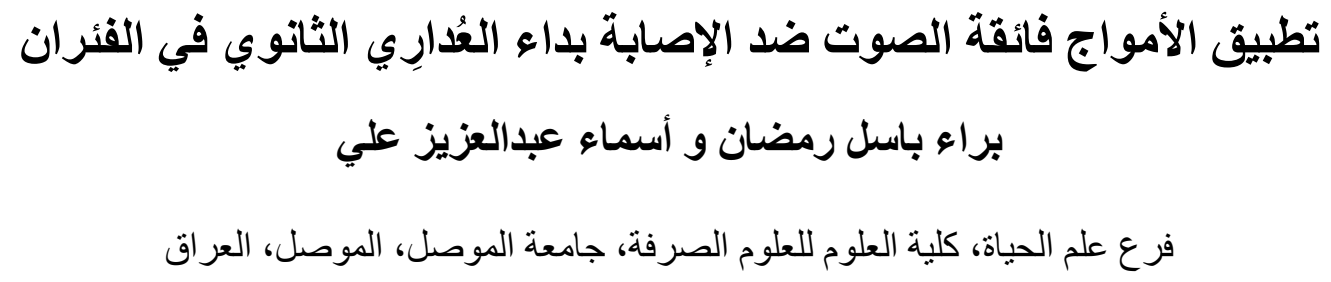

الخلاصة

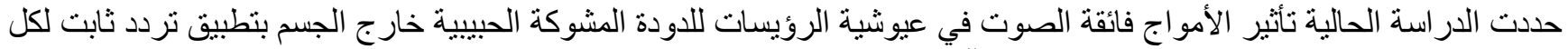

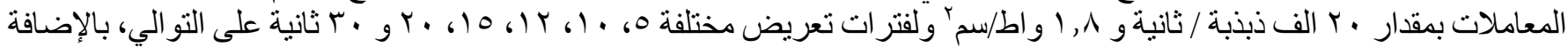

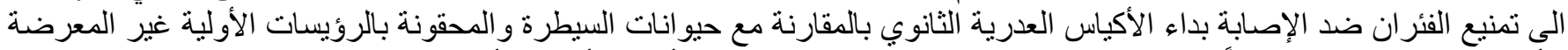

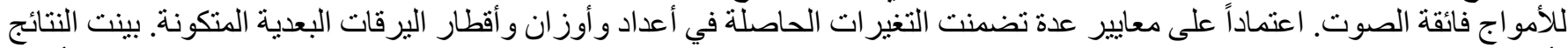

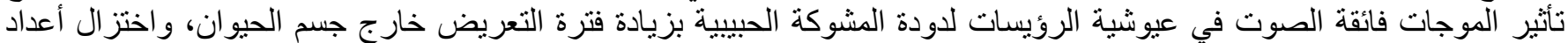

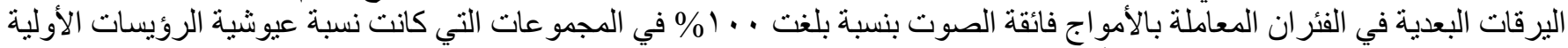

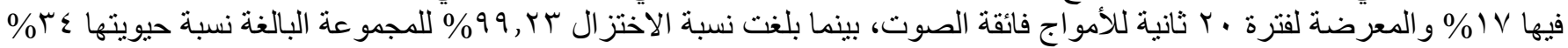

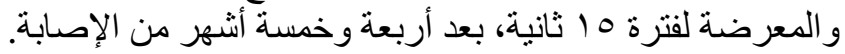

\section{Introduction}

Hydatidosis is one of the most important parasitic infections on public and veterinary health worldwide. The disease has significant economic importance concerning mortality and morbidity (1-3) as estimated losses of global production of livestock are two billion dollars (4). The disease has a wide geographical scope and occurs in all 
continents, including the tropical and subtropical regions. Cystic echinococcosis (hydatid cyst) (CE) was diagnosed by the basic methods of clinical examination, imaging and serological tests (5-7). CE is treated by a variety of ways, including chemical therapy (drug therapy), percutaneous aspiration injection and respiration (PAIR), surgical treatment, or the option of observation without surgical intervention $(8,9)$. Chemotherapy involves the use of albendazole, mebendazole or benzimidazole carbamates, chemotherapy is recommended as the only option in cases. where surgical treatment is not possible or when multiple cysts are available (9). This option includes aspiration of the fluid, injection of lethal agents and re-suction. The noninvasive control option is carried out with the CE4-CE5 stages of cyst development according to the world health organization (WHO) classification to avoid the possibility that these cysts remain fertile. Ultrasound and Serological tests are used for surveillance.

Ultrasound waves are waves with a frequency greater than $20 \mathrm{KHZ}$ (human hearing threshold) $(10,11)$. These are inaudible high-frequency mechanical vibrations produced by the electric generator and are converted to acoustic energy by mechanical deformation of a piezoelectric crystal placed in the power transformer (12). Ultrasonic frequency can be classified primarily into two sections: low-power highfrequency diagnostic ultrasound in the MHZ range, and the low-frequency high-power ultrasound is in the KHZ range. Ultrasound waves are a physical therapeutic method where non-ionizing radiation is applied in the form of mechanical sonicated on the tissues to produce heat. Ultrasound has been used to detect variety of diseases, including parasitic infections since 1970 (13), High Intensity Focused Ultrasound (HIFU) was initially used to treat cancer (14). It was used in the 1940s to treat brain diseases such as Parkinson's disease (15), uterine fibroids and prostate tumors (16). Ultrasound waves have also been used extensively in medical diagnostics and increasingly for therapeutic purposes as they have been applied to break up kidney stones, as a surgical tool for the removal of tumor tissue and as a tool for administration of drugs (17).

Hence the aims of this study were to show the impact of ultrasound in with the vitality of different concentration of protoscolices in vitro and in the prevention of albino mice from infection with hydatidosis. This study is considered as a first study in the country regarding application of ultrasound against hydatidosis.

\section{Materials and methods}

\section{Segregation and testing hydatid cysts}

The hydatid cysts were found (Figure 1) after being separated from liver of slaughtered sheep, which collected from butchers' shops in Mosul, and upon arrival in the laboratory, hydatid cysts were examined to ascertain the vitality.

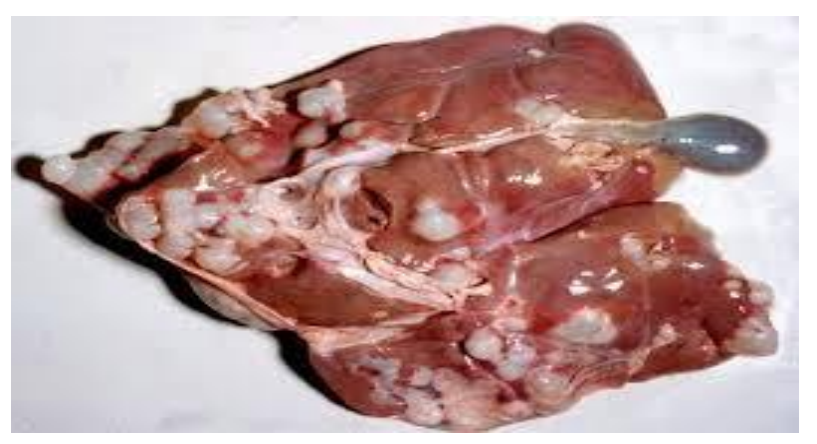

Figure 1: Hydatid cysts (hydatid cysts) in the liver of sheep.

Collection and assessment of $\boldsymbol{E}$. granulosus protoscolices

Sheep cysts containing protoscolices were obtained under sterilized conditions, a live protoscolices, $20 \mu \mathrm{l}$ of protoscolices suspension were added to $20 \mu \mathrm{l}$ of $0.1 \%$ of eosin pigment on a slide, then tested under light microscope. Bright green protoscolices were considered as alive because of eosin exclusion by protoscolices membranes, whereas red protoscolices were regarded as dead because of acceptance of the pigment. Gained and counted according to authenticated manner (18).

\section{Experimental animals}

120 Albino mice (four to five weeks old) were used and cared for in the Department of Biology, College of Education for Pure Sciences, University of Mosul, according to the conditions required for the experiments.

\section{The device used in the experiment}

The ultrasonic waves device was used, catalogue number 1/96/40/80/3/4 supplied by the Omni international (Figure 2).

\section{Effect of the ultrasound waves on the vitality of sheep protoscolices in vitro}

To determine the effect of ultrasound waves on the vitality of protoscolices in vitro within a certain time and frequency of 20.000 pulse/second, protoscolices with a $100 \%$ viability were taken at a concentration of 2000 protoscolex $/ \mathrm{ml}$, and then exposed to the ultrasonic waves, amount of ice was placed around the sample to avoid high temperature during exposure. Samples were exposed for 30 , $20,15,12,10$ and 5 seconds, the post exposure vital percentages were $0,17,34,50,80$ and $90 \%$ respectively. The protoscolices were examined under a light microscope for viability taking into consideration the flame cells movement, morphological abnormalities, and exclusion of eosin pigment. 


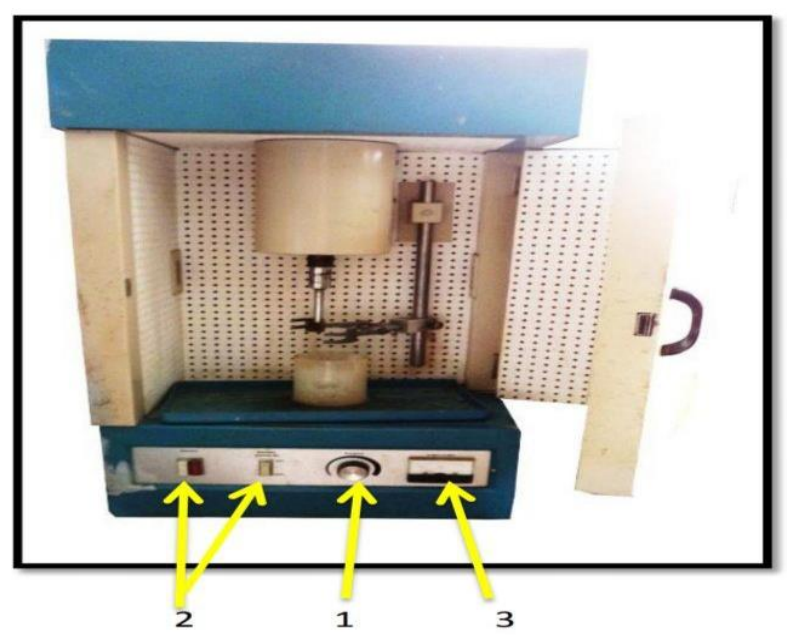

Figure 2: Ultrasound waves device. (1) Operating power, (2) Main and power stand by for operation too when the sample is exposed, (3) the amplitude capacity starts from $0-28$, the frequency is 20 thousand vibration/second.

\section{Effect of ultrasound waves in protoscolices injected in vivo}

protoscolices with vitality $90,80,50,34,17$ and $0 \%$ were selected for mice injection in addition to the control with $100 \%$ vitality. A total of 30 male mice, aged 5-3 weeks, were divided into six group (five mice/ each group). The $1^{\text {st }}$ group was injected with 2000 protoscolices of vitality $0 \%$. The $2^{\text {nd }}$ group was injected with 2000 protoscolices of vitality $17 \%$. The $3^{\text {ed }}$ group was injected with 2000 protoscolices of vitality $34 \%$. The $4^{\text {th }}$ group was injected with 2000 protoscolices of vitality $50 \%$. The $5^{\text {th }}$ group was injected with 2000 protoscolices of vitality $80 \%$. The $6^{\text {th }}$ group was injected with 2000 protoscolices of vitality $90 \%$. The $7^{\text {th }}$ group (control) was injected with 2000 protoscolices of vitality $100 \%$. All groups were all dissected after 2, 3, 4, 5 months.

\section{Statistical analysis}

Results of this study were analyzed statistically based on Completely Randomized Design (CRD) to study the effect of intervals and exposures and the integration between them, then the differences between the averages of each factor and the compatibility between factors were estimated depending on Duncan's Multiple Range Test (DMRT). Statistical Analysis System (SAS version 9) was utilized for applied for data analysis (19).

\section{Results}

Table 1 exhibited the changes in the numbers, diameters and weights of the hydatid cysts, and the of significance of $\mathrm{F}$ in the ANOVA analysis, table 2 DMRT for averages test explained a decrease in the average number of hydatid cysts in the treated groups (Figure 3,5,7 and 8) compared to control animals (Figure 4 and 6). The treated mice exhibited a reduction in the number of cysts 0.000 at $30 \mathrm{sec}$ exposure, while control mice displayed the highest average of 9.650, 5 months post infection. Table 3 demonstrated the highest percentage reduction of hydatid cysts number in treated mice at 30 seconds exposure followed by 20, 15,12,10 and 5 seconds, respectively.

Table 1: Effect of ultrasound on numbers, diameters and weights of hydatid cysts in all experience animals

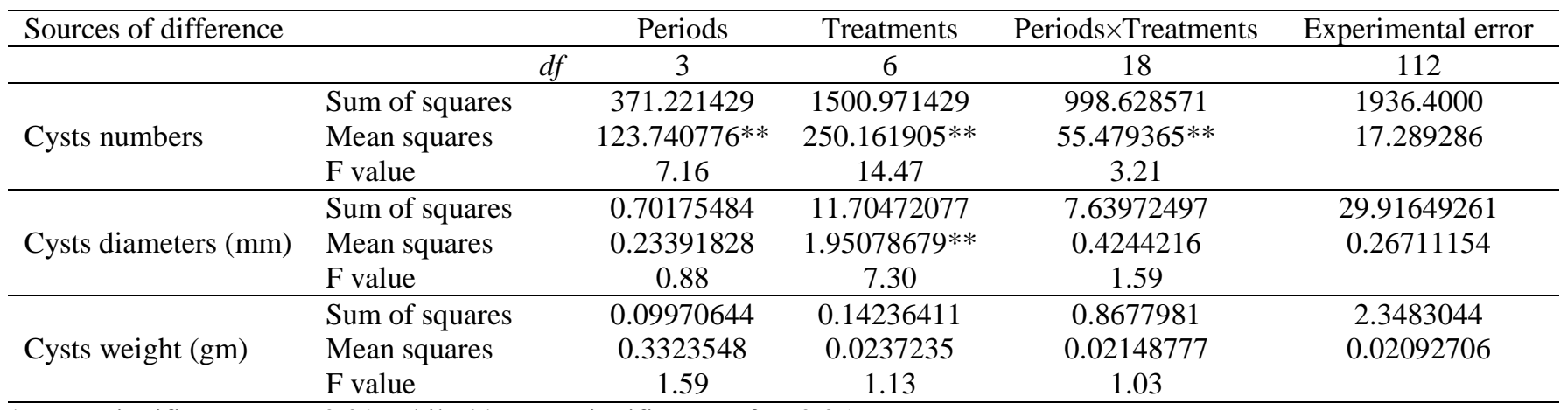

* mean significance at $\mathrm{P}<0.01$, while $* *$ mean significance of $\mathrm{P}<0.05$.

Diameters are shown in table 1 illustrated $\mathrm{F}$ significance, table 4 (DMRT) for averages revealed significant differences between the exposure and non-exposed at 30 and 20 seconds. Significant differences were also observed between mean averages compatibility exposure and period, metacestode diameters in mice injected with protoscolices exposed with ultrasound decreased, with a minimum 5 months post injury $0,000 \mathrm{~mm}$ at 30 seconds exposure, followed by $20,15,12$, 10 and 5 seconds respectively, contrast to the hydatid cysts control group was $0.890 \mathrm{~mm}$. Related to the weight of the hydatid cysts table 1 showed $\mathrm{F}$ insignificancy for interference between the two factors (exposure and period). 
However, the DMRT (Table 5) showed significant differences between the averages of compatibility regarding periods and exposures. The cysts weights in treated animals decreased to $0.00 \mathrm{mg}$ at 30 seconds and all months followed by $20,15,12,10$ and 5 seconds, respectively, in contrast to the control group $(0.2760 \mathrm{mg}) 5$-month post injury.

Table 2: Effect of ultrasound waves on the number of hydatid cysts in treated animals

\begin{tabular}{lccccc}
\hline Periods in & 2 months & 3 months & 4 months & 5 months & Average \\
\hline Control & $0.800 \mathrm{c}$ & $3.200 \mathrm{c}$ & $14.600 \mathrm{ab}$ & $19.200 \mathrm{a}$ & $9.650 \mathrm{a}$ \\
30 seconds & $0.000 \mathrm{c}$ & $0.000 \mathrm{c}$ & $0.000 \mathrm{c}$ & $0.000 \mathrm{c}$ & $0.000 \mathrm{c}$ \\
20 seconds & $0.000 \mathrm{c}$ & $0.000 \mathrm{c}$ & $0.000 \mathrm{c}$ & $0.40 \mathrm{c}$ & $0.10 \mathrm{c}$ \\
15 seconds & $0.20 \mathrm{c}$ & $0.40 \mathrm{c}$ & $0.20 \mathrm{c}$ & $0.20 \mathrm{c}$ & $0.25 \mathrm{c}$ \\
12 seconds & $0.20 \mathrm{c}$ & $1.20 \mathrm{c}$ & $0.60 \mathrm{c}$ & $1.60 \mathrm{c}$ & $1.10 \mathrm{c}$ \\
10 seconds & $0.40 \mathrm{c}$ & $0.20 \mathrm{c}$ & $1.20 \mathrm{c}$ & $2.40 \mathrm{c}$ & $0.65 \mathrm{c}$ \\
5 seconds & $0.80 \mathrm{c}$ & $1.40 \mathrm{c}$ & $3.80 \mathrm{c}$ & $9.60 \mathrm{~b}$ & $3.90 \mathrm{~b}$ \\
\hline Average & $0.4571 \mathrm{c}$ & $1.00 \mathrm{bc}$ & $2.9142 \mathrm{ab}$ & $4.5714 \mathrm{a}$ & \\
\hline
\end{tabular}

The different letters indicate significance, while the similar letters indicate insignificancy.

Table 3: Percentage of protoscolices reduction in treated animals for all months

\begin{tabular}{lcccc}
\hline \multirow{2}{*}{ Periods } & \multicolumn{5}{c}{ Months } & 5 \\
\cline { 2 - 5 } & 2 & 3 & 4 & $51.34 \%$ \\
5 second & $50 \%$ & $63.08 \%$ & $65.25 \%$ & $75 \%$ \\
10 second & $60 \%$ & $62.368 \%$ & $75 \%$ & $98 \%$ \\
12 second & $65.38 \%$ & $87.5 \%$ & $92.5 \%$ & $99.23 \%$ \\
15 second & $87.5 \%$ & $97.5 \%$ & $98.66 \%$ & $100 \%$ \\
20 second & $100 \%$ & $100 \%$ & $100 \%$ & $100 \%$ \\
30 second & $100 \%$ & $100 \%$ & $100 \%$ & 5 \\
\hline
\end{tabular}

Table 4: Effect of ultrasound waves on diameters of hydatid cysts in treated animals

\begin{tabular}{|c|c|c|c|c|c|}
\hline Periods & 2 months & 3 months & 4 months & 5 months & Average \\
\hline Control & $0.1002 \mathrm{de}$ & $0.20570 \mathrm{de}$ & $1.087 \mathrm{ab}$ & $1.2838 \mathrm{a}$ & $0.8900 \mathrm{a}$ \\
\hline 30 second & $0.000 \mathrm{e}$ & $0.000 \mathrm{e}$ & $0.000 \mathrm{e}$ & $0.000 \mathrm{e}$ & $0.000 \mathrm{e}$ \\
\hline 20 second & $0.000 \mathrm{e}$ & $0.000 \mathrm{e}$ & $0.000 \mathrm{e}$ & $0.226 \mathrm{de}$ & $0.0565 \mathrm{~d}$ \\
\hline 15 second & $0.200 \mathrm{de}$ & $0.177 \mathrm{de}$ & $0.006 \mathrm{e}$ & $0.2454 \mathrm{de}$ & $0.2334 \mathrm{ed}$ \\
\hline 12 second & $0.228 \mathrm{de}$ & $0.7277 \mathrm{abcd}$ & 0.388 bcde & 0.706 abcde & $0.2723 \mathrm{bcd}$ \\
\hline 10 second & $0.056 \mathrm{de}$ & $0.0672 \mathrm{~d}$ & 0.7100 abcde & 0.7016 abcde & $0.4179 \mathrm{bc}$ \\
\hline 5 second & 0.5870 abcde & 0.3094 cde & $0.8104 \mathrm{abcd}$ & $1.0438 \mathrm{abc}$ & $0.5965 \mathrm{ab}$ \\
\hline Average & $0.3083 \mathrm{a}$ & $0.2873 \mathrm{a}$ & $0.344 \mathrm{a}$ & $0.4699 \mathrm{a}$ & \\
\hline
\end{tabular}

The different letters indicate significance, while the similar letters indicate insignificancy.

Table 5: Effect of ultrasound waves on weight of hydatid cysts in treated animals

\begin{tabular}{lccccc}
\hline \multirow{2}{*}{ Periods } & \multicolumn{4}{c}{ Treatments in month } & \multirow{2}{*}{ Average } \\
\cline { 2 - 5 } & 2 & 3 & 4 & 5 & $0.09304 \mathrm{a}$ \\
Control & $0.03272 \mathrm{bc}$ & $0.02298 \mathrm{bc}$ & $0.0653 \mathrm{bc}$ & $0.27600 \mathrm{a}$ & $0.000 \mathrm{c}$ \\
30 second & $0.000 \mathrm{c}$ & $0.000 \mathrm{c}$ & $0.000 \mathrm{c}$ & $0.000 \mathrm{c}$ & $0.00395 \mathrm{a}$ \\
20 second & $0.000 \mathrm{c}$ & $0.000 \mathrm{c}$ & $0.000 \mathrm{c}$ & $0.0188 \mathrm{bc}$ & $0.03704 \mathrm{a}$ \\
15 second & $0.0002 \mathrm{c}$ & $0.007 \mathrm{c}$ & $0.002 \mathrm{c}$ & $0.02186 \mathrm{bc}$ & $0.03803 \mathrm{a}$ \\
12 second & $0.00866 \mathrm{bc}$ & $0.03686 \mathrm{bc}$ & $0.03070 \mathrm{bc}$ & $0.05397 \mathrm{a} \mathrm{bc}$ & $0.063210 \mathrm{a}$ \\
10 second & $0.0094 \mathrm{bc}$ & $0.05068 \mathrm{bc}$ & $0.08085 \mathrm{ab} \mathrm{c}$ & $0.07697 \mathrm{abc}$ & $0.07085 \mathrm{a}$ \\
5 second & $0.04276 \mathrm{bc}$ & $0.01120 \mathrm{bc}$ & $0.14316 \mathrm{ab} \mathrm{c}$ & $0.23056 \mathrm{ab}$ & $0.08415 \mathrm{a}$ \\
\hline Average & $0.01339 \mathrm{a}$ & $0.02765 \mathrm{a}$ & $0.04973 \mathrm{a}$ & & \\
\hline
\end{tabular}

The different letters indicate significance, while the similar letters indicate insignificancy. 


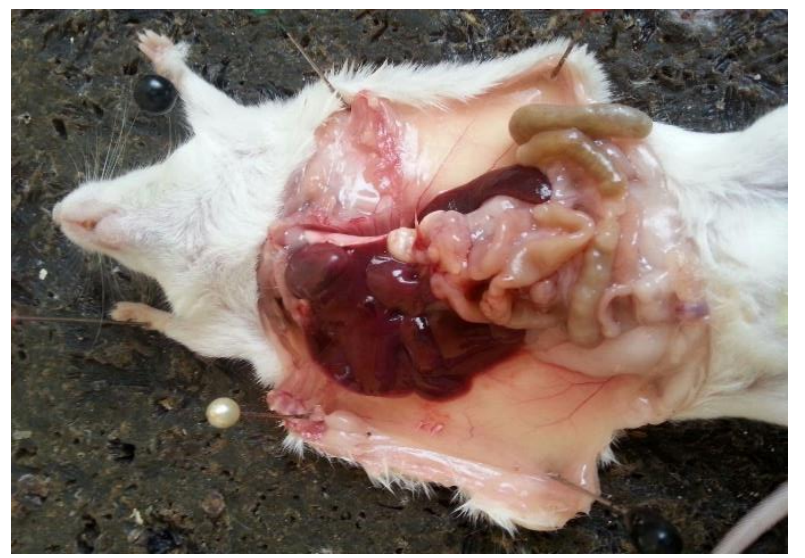

Figure 3: The absence of cysts in animals injected with protoscolices and exposure to ultrasound for 20 Seconds after 3 months.

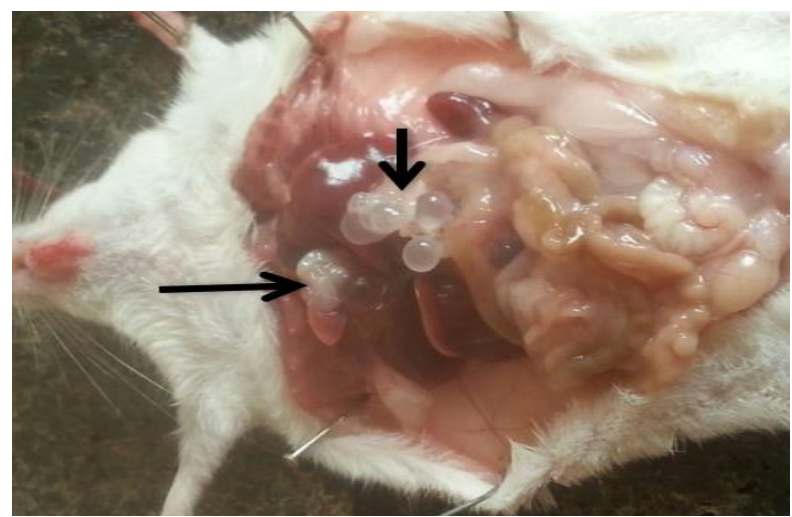

Figure 4: Growing hydatid cysts (black arrows) in untreated animals after 4 months of infection.

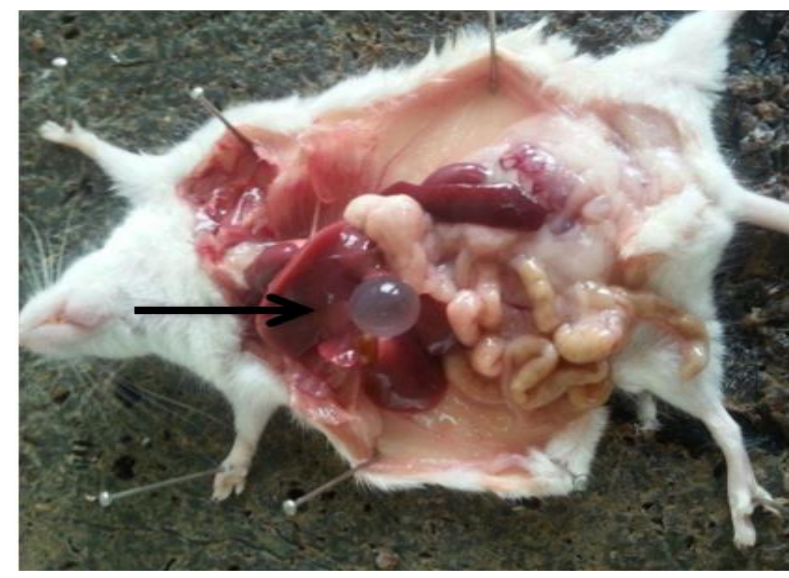

Figure 5: Growing hydatid cysts (black arrow) in animal treated with ultrasound waves for 5 Seconds after 4 months of infection.

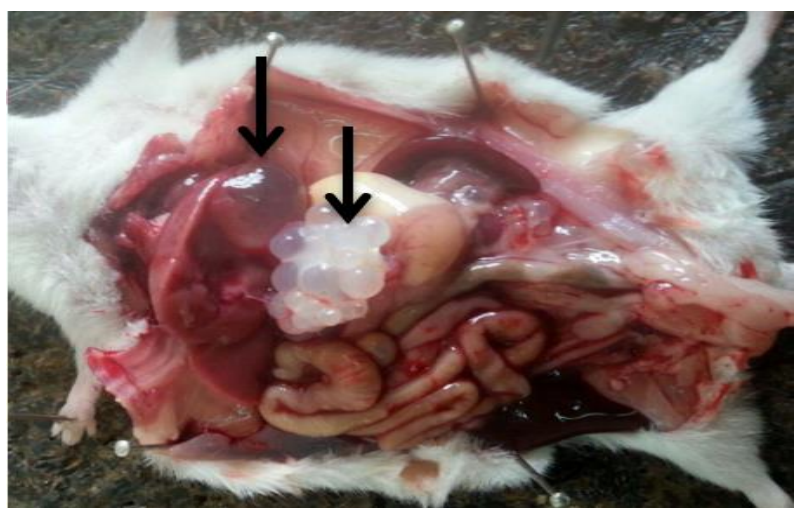

Figure 6: Growing hydatid cysts in (black arrows) in untreated animals (control) after 5 months of infection.

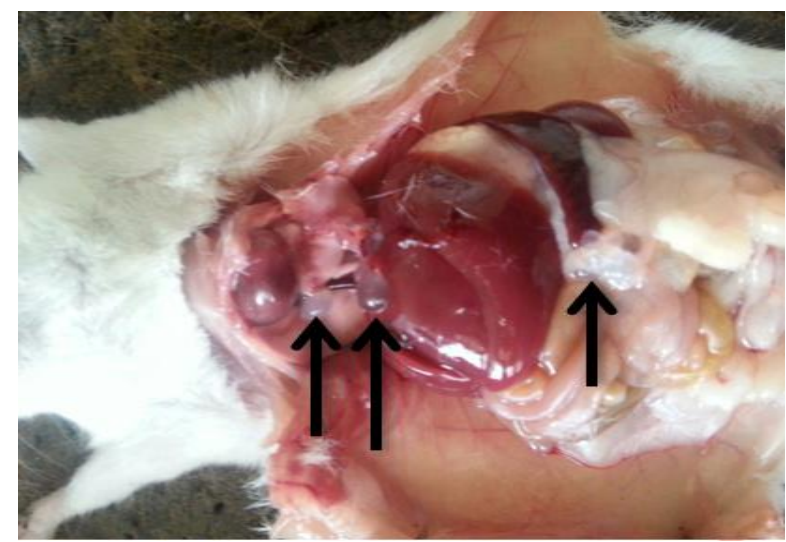

Figure 7: Growing hydatid cysts (black arrows) in the animal treated with ultrasound waves for 5 Seconds after 5 months of infection.

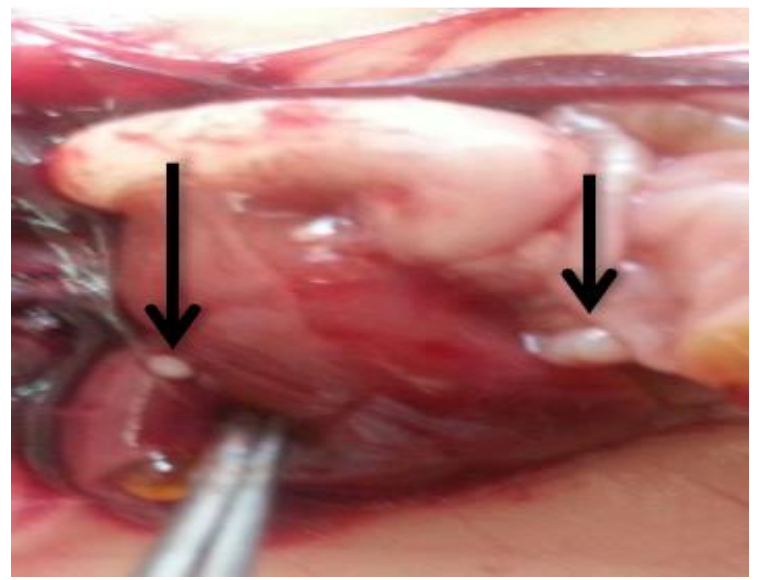

Figure 8: Growing hydatid cysts (black arrows) in animal treated with ultrasound waves for 12 Seconds after 3 months of infection. 


\section{Discussion}

The effects of ultrasound waves on cells are divided into two categories: Total effects such as disintegration or influence on cell division capacity and damage to cellular infrastructure, and fine effects such as chromosomal changes, functional changes and heterogeneous growth patterns (17).

The results of electron microscope examination of cells and tissues post exposure to ultrasound waves showed damage of a variety of cellular organelles such as mitochondria at first, lysosomes, causing the release of enzymes in the cell, as well as membrane and mitochondrial damage due to cavitation (17). Cytogenetic studies on the effect of ultrasound waves by other researchers on chromosomes have indicated that high intensity ultrasound waves can cause DNA degradation. It seems that the damage is caused by hydrodynamic shear stresses, free radical formation or overheating that caused by cavitation. Ultrasound waves can cause genetic changes, such as modifying histone structure which can have a long-term effect on gene expression (17). All these explanations illustrate the increased reduction in the cysts and the low numbers of cysts in mice injected with protoscolices exposure to ultrasound.

The results of this study showed that the numbers, weights and diameters of the cysts were reduced in addition to the high reduction rate in the treated mice compared to the control group for all months.

Current study results have shown similarity with those of other researchers revealing that high intensity ultrasound resection efficacy in uncomplicated cases of patients with Echinococcus multilocularis in the liver, implying the destruction of protoscolices, lamellar and germinal layers of the alveolar cyst larvae causing death of morphologically transformed cells which in turn cause liver necrosis (14). Results of biopsy examination after eradication confirmed the damage of impact to protoscolices and cellular components in the alveolar cysts, thus high intensity focused ultrasound considered a promising treatment for alveolar echinococcosis (14), also Imankulov et al. (20) observed the destructive changes on alveococcosis with irregular forms and destroyed structures of the outer cuticular membrane, increase in neutrophil cells, eosinophils and macrophages. Thin sections showed membranes of alveolar cysts with different thickened dissociated and ripped, and the cells of germinal layer were desquamated and the nuclei of cells were lysed and the cytoplasm was vacuolated. The electron microscope showed destruction of the outer cytoplasmic membrane of germ cells, these effects were attributed to the double cavitation and necrosis upon exposure to high intensity focused ultrasound waves (20).
The results of the present study exhibited an consistency with another study, concerning the action of high intensity focused ultrasound waves to treat cystic echinococcosis in the liver, represented by destructive impact on protoscolices with membrane cavitation (21). Treatment of 42 patients (68\%) with liver echinococcosis out of 62 patients, with high intensity focused ultrasound waves, exhibited a clinical response represented by cysts elimination, decrease of (50\%) of cysts size in patients, and absence of cystic echinococcosis recurrence after 3 years of treatment. A 7 patients undergone conventional surgical treatment revealed cysts disappearance, a decrease by $50 \%$ of cyst size, and absence of cystic echinococcosis recurrence after 3 years of treatment, which prove high intensity focused ultrasound effectiveness as a treatment of choice or as a post-operative adjunct to prevent the spread of parasite (21). Zhang et al. (22) showed the effect of high intensity focused ultrasound (HIFU) with the addition of superabsorbent polymer (SAP) on E. granulosus protoscolices vitality in vitro, the HIFU effect was increased after the addition of superabsorbent polymer due to increased temperature of cystic fluid to about $60^{\circ} \mathrm{C}$, which caused protein denaturation, cell necrosis, and increase of protoscolices death, this was explained by Moazeni et al. (23) as he considered warm water as a protoscolicidal factor at temperature ranging between 50 $60^{\circ} \mathrm{C}$.

In addition to the effect of cavitation in killing protoscolices subjected to HIFU, which crashed into small fragments.

Acoustic cavitation is responsible for rupture of long chained organic structures that make up microorganisms. These mechanical effects were invested in disinfecting water contaminated with microbial spores and protozoa, such as Cryptosporidium parvum, within 10 minutes of exposure to ultrasonic waves (24). On the other hand, these properties have also been used to eliminate water contamination with Giardia spp. Cavitation causes mechanical rupture of molecules that make up organisms (24). Other researchers have studied the effect of ultrasound waves on the vitality of Cryptosporidium spp. in the waste water, it was noticed that after 5 minutes of ultrasound wave exposure,50\% of cysts were dead, while at 30 minutes of exposure $90 \%$ of cysts were dead, they observed that as the temperature increased due to the effect of cavitation there was an increase in activity disruption of Cryptosporidium parvum. Initial exposure to ultrasound waves has been shown to decrease numbers of Giardia spp. When researchers applied ultrasonic exposures at 720-360 KJ (Kilo Joules) to sewage samples $62.5 \%$ of cyst were dead, and at a dose of $14400 \mathrm{KJ}$, approximately $80 \%$ of Giardia cysts were eliminated (23).

It can be said that ultrasound waves can be applied in the future through prospective studies as an effective therapeutic method for the treatment of Hydatidosis in human. 


\section{Conclusion}

It may well be concluded ultrasound has a significant impact on the viability of protoscolices of Echinococcus granulosus in vitro and in BALB/c mice, and may be used in the future as a promising therapeutic method for cystic echinococcosis.

\section{Acknowledgements}

The researchers would like to acknowledge Education College for Pure Sciences, College of Science/ University of Mosul for supporting the current study.

\section{Conflict of interests}

The authors declare no conflict of interests.

\section{References}

1. Matallah F, Khleaiphia W, Lamari S, Matallah S. Gastrointestinal helminth parasites of dogs in rural areas of the north east of Algeria. Iraqi J Vet Sci. 2018;32(1):93-98. Doi: http://dx.doi.org/10.33899/ ijvs.2018.153829

2. Hasona NA, Amer OH, Morsi A, Raef A. Comparative biochemical, parasitological, and histopathological studies on cystic echinococcosis in infected sheep. Comp Clin Pathol. 2017:26(4):805-810. doi: 10.1007/s00580-017-2450-2

3. Yousif SY, Ali AA. Effect of probiotic acidophilus plus against infection with secondary hydatid disease in BALB /c mice. Iraqi J Vet Sci. 2020;34(1):115-121. Doi: 10.33899/ijvs.2019.125613.1104

4. Pakala T, Molina M, Wu GY. Hepatic echinococcal cysts: A review. J Clinical Trans Hepatol. 2016;4(1):39. Doi: $\underline{10.14218 / \mathrm{JCTH} .2015 .00036}$

5. Brunetti E, Kern P, Vuitton DA. Expert consensus for the diagnosis and treatment of cystic and alveolar echinococcosis in humans. Acta Trop. 2010;114(1):1-16. Doi: 10.1016/j.actatropica.2009.11.001

6. Khanbabaie S, Riazi M, Chang $\mathrm{CH}$, Yunus $\mathrm{MH}$, Noordin R. Lateral flow dipstick antigen assay for human cystic echinococcosis. Acta Trop. 2019;190:171-176. Doi: 10.1016/j.actatropica.2018.11.018

7. Zhang W, Wen H, Li J, Lin R, McManus DP. Immunology and immunodiagnostic of cystic echinococcosis: An update. Clin Develop Immunol. 2011;2012:1-12. Doi: 10.1155/2012/101895

8. Kern P, da Silva AM, Akhan O, Müllhaupt B, Vizcaychipi KA, Budke C, Vuitton DA. The echinococcoses: Diagnosis, clinical management and burden of disease. Advan Parasitol. 2017;96:259-369. Doi: $10.1016 /$ bs.apar.2016.09.006

9. Diaz A. Immunology of cystic echinococcosis (hydatid disease). British Med Bull. 2017;1-13. doi: https://doi.org/10.1093/bmb/ldx033

10. Knorr D, Zenker M, Heinz V, Lee DU. Applications and potential of ultrasonics in food processing. Trends Food Sci Technol. 2004;15(5):261-266. Doi: 10.1016/j.tifs.2003.12.001

11. O'sullivan J, Murray B, Flynn C, Norton I. The effect of ultrasound treatment on the structural, physical and emulsifying properties of animal and vegetable proteins. Food Hydrocolloids. 2016: 53, 141-154. Doi: 10.1016/j.foodhyd.2015.02.009

12. Samaneh R, Ali Y, Mostafa J, Mahmud NA, Zohre R. Laser therapy for wound healing: A review of current techniques and mechanisms of action. Biosci Biotech Res Asia. 2015;12:217-23. Doi: $10.13005 / \mathrm{bpj} / 866$

13. Mirabile E, Solomon N, Fields PJ, Macpherson CNL. Progress towards international adoption of the World Health Organization ultrasound classification of cystic echinococcosis. Acta Trop. 2019;189:6-9. Doi: 10.1016/j.actatropica.2018.09.024

14. Zhampeissov N, Manap E, Rustemova K, Fedotovskikh G, Tuganbekov T, Imankulov S, Gaipov A. High-intensity focused ultrasound ablation: a non-surgical approach to treat advanced and complicated liver alveococcosis. J Med Ultraso. 2019;46(2):251-255. Doi: 10.1007/s10396-018-0914-x

15. She WH, Cheung TT, Jenkins CR, Irwin MG. Clinical applications of high-intensity focused ultrasound. Hong Kong Med J. 2016;22(4):38292 DOI: $10.12809 / \mathrm{hkmj} 154755$

16. Yudina A, Moonen C. Ultrasound-induced cell permeabilization and hyperthermia: strategies for local delivery of compounds with intracellular mode of action. Inter J Hyperthermia. 2012;28(4):311-319. Doi: 10.3109/02656736.2012.664307.

17. Izadifar Z, Babyn P, Chapman D. Mechanical and biological effects of ultrasound: A review of present knowledge. Ultrasound Med Biol. 2017;43(6):1085-1104

Doi: 10.1016/j.ultrasmedbio.2017.01.023. Epub 2017 Mar 23.

18. Smyth JD, Barrett NJ. Procedures for testing the viability of human hydatid cysts following surgical removal, especially after chemotherapy. Trans Royal Soc Trop Med Hyg. 1980: 74(5), 649-652. Doi: 10.1016/0035-9203(80)90157-1.

19. Al-Zubaidy KM, Al-Falahy MD. Principles and procedures of statistics and experimental design. $1^{\text {st }}$ ed. Duhok: University of Duhok Printing Press; 2016. 395 p.

20. Imankulov SB, Fedotovskikh GV, Zhampeissov NK, Yerlan M, Shaimardanova GM, Knaub LV. Treatment of liver alveococcosis with high-intensity focused ultrasound. Ultrason Sonochem. 2015;27:707711. Doi: 10.1016/j.ultsonch.2015.05.022.

21. Yuan Q, Li B, Jiang S, Zhao Q, Duo J, Huang X. Gamma-Ray treatment of echinococcus protoscoleces prior to implantation in mice reduces echinococcosis. Biomed Res Inter. 2016;2016:1-9. Doi: $\underline{10.1155 / 2016 / 9027489}$

22. Zhu J, Zhu H, Mei Z, Zhang L, Jin C, Ran L, Zhou K, Yang W. Highintensity focused ultrasound ablation for treatment of hepatocellular carcinoma and hypersplenism. Br J Radiol. 2014;87(1043):20140374. Doi: $10.1259 /$ bjr.20140374

23. Moazeni M, Alipour CM. Echinococcus granulosus: In vitro effectiveness of warm water on protoscolices. Ex Parasitol. 2011;127(1):14-17. Doi: 10.1016/j.exppara.2010.06.021

24. Passos TM, da Silva LH, Moreira LM, Zângaro RA, da Silva SR, Fernandes FB, Fernandes AB. Comparative analysis of ozone and ultrasound effect on the elimination of Giardia spp. cysts from wastewater. Sci Eng. 2014;36:138-143. Doi: $\underline{10.1080 / 01919512.2013 .864227}$ 